\title{
I know what the studies say, but what should I do for my patient?
}

\author{
Paul Kurlansky, MD
}

See related article on pages 1302-9.

Threatening the remarkable progress in the treatment of cardiovascular disease is the virtual epidemic of obesity and the consequent increased incidence of diabetes. The prevalence of diabetes has more than doubled in the past decade, with current estimates predicting an incidence between 1 in 5 and 1 in 3 adults by the year 2050. ${ }^{1}$ People with diabetes are more than twice as likely to have cardiovascular disease develop, and at least $65 \%$ will die of such disease. Diabetes affects vascular physiology on multiple levels and tends to manifest with diffuse, multivessel involvement. ${ }^{2}$ It is perhaps for this reason that the more "vessel-directed" surgical rather than "lesion-directed" percutaneous coronary intervention (PCI) approach has proved more successful in this population. Both randomized, controlled trials and retrospective registry reviews have documented a survival benefit associated with surgical revascularization in patients with diabetes who have multivessel disease. ${ }^{3-9}$ The potential impact of newer generation drug-eluting stents on improving these results remains to be seen. ${ }^{10}$

The challenges of comparing procedure-related outcomes are considerable. Unlike a medication, which can be biochemically defined and whose dosage and pharmacokinetics can be quantified, each procedure is subject to subtleties of technique, nuances of clinical judgment, and intricacies of care that can vary in ways that defy even the most insightful of analytic approaches. It is in this gray zone of clinical ambiguity that many, if not most, patients actually reside. It this very uncertainty that Nauffal and colleagues ${ }^{11}$ seek to address in their report in this issue of the Journal. Retrospective analysis of 1583 patients with diabetes undergoing coronary artery bypass grafting $(\mathrm{CABG})$ with triple-vessel disease in a single institution revealed 202 who had previously undergone PCI with stenting. Both Cox regression and propensity score-matching approaches demonstrated a clear association of previous stenting with diminished 5-year survival. Certainly, one conclusion that could be

From the Department of Surgery, Columbia University, New York, NY.

Disclosures: Author has nothing to disclose with regard to commercial support.

Received for publication Feb 3, 2015; accepted for publication Feb 4, 2015; available ahead of print March 17, 2015.

Address for reprints: Paul Kurlansky, MD, Department of Surgery, Columbia University, Black Building 210, 650 W 168th St, New York, NY 10032 (E-mail: pk2245@ cumc.columbia.edu).

J Thorac Cardiovasc Surg 2015;149:1310-1

$0022-5223 / \$ 36.00$

Copyright (c) 2015 by The American Association for Thoracic Surgery

http://dx.doi.org/10.1016/j.jtcvs.2015.02.007 drawn from these findings is that stenting in patients with diabetes compromises subsequent surgical options and actually deprives patients of the optimal benefit that might be achieved from CABG surgery. Unfortunately, the limitations of the available data did not permit Nauffal and colleagues ${ }^{11}$ to explore the specific indications for stent deployment, the extent of disease at the time of stenting, the choice of stent (bare metal vs drug eluting and first vs second generation), the patient's SYNTAX score, or the interval between PCI and subsequent $\mathrm{CABG}$. It is therefore unclear whether surgery at the time of PCI might have altered the patients' clinical course, or whether the surgical option would even have been appropriate. An equally plausible hypothesis might therefore suggest that the appropriate need for previous stenting distinguished a subset of patients with more aggressive disease who therefore died earlier.

It is therefore wise to permit clinical observation to be informed by physiologic reality. PCI addresses the obstructing atherosclerotic lesion, restoring circulation to the downstream vascular bed. If angioplasty is the art of controlled injury, stenting further manipulates the healing response to provide an open conduit. As Nauffal and colleagues ${ }^{11}$ note in their discussion, local and systemic inflammatory responses, as well as endothelial injury, alterations of local shear stresses, and foreign-body reaction, have all been implicated in the body's response to stents. It should not be overlooked, however, that the marginal overall morbidity when compared with even the least invasive of surgical approaches is no small matter, especially in the emerging era of patientcentered outcomes. Surgical revascularization, by focusing on the downstream circulation directly, is somewhat immune to the complexity of the lesion itself. It is important to note, however, that not all graft conduits are created equal. A recent report from the Radial Artery Patency Study (RAPS) provides compelling evidence for the superiority of the radial artery relative to the saphenous vein in revascularization of the patient with diabetes. ${ }^{12}$ Moreover, despite considerable surgical reluctance to risk deep sternal wound infection, several studies have documented improved long-term survival (with no increased sternal wound infection) associated with the use of bilateral internal thoracic arteries in patients with diabetes. ${ }^{13,14}$ Although the presumption regarding the superiority of internal thoracic artery grafting has classically centered around demonstrably improved graft patency, it should not be forgotten that among the reasons for this improved patency is the physiologic milieu favoring enhanced nitric oxide production, which therefore promotes vasodilatation, inhibits thrombosis and atherosclerosis, and supports the health and viability of the endothelium 


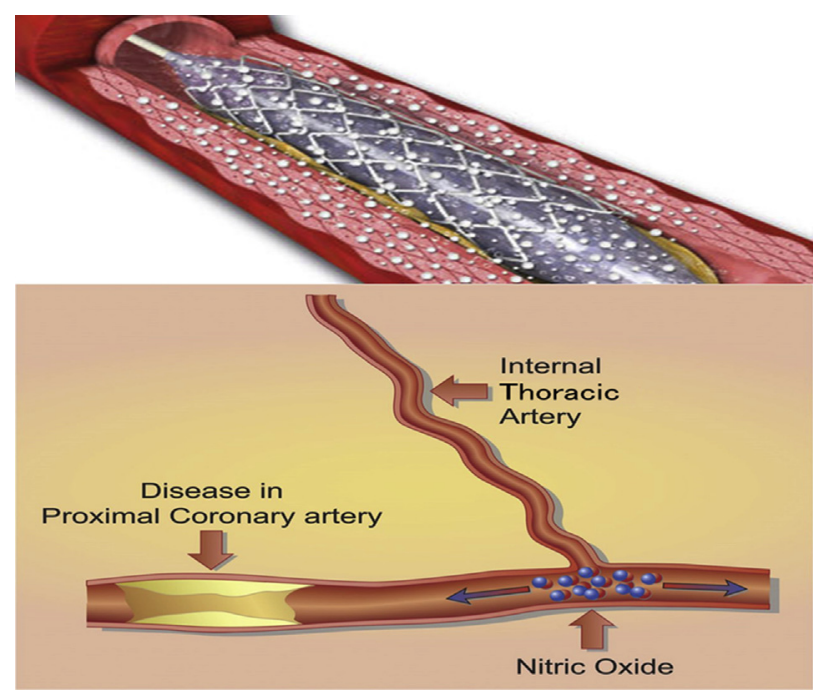

FIGURE 1. Stenting addresses the lesion directly, while the internal thoracic artery favors enhanced nitric oxide production, promoting downstream vasodilatation, inhibiting thrombosis and atherosclerosis, and supporting the health and viability of the endothelium.

(Figure 1). ${ }^{15-17}$ These properties in fact may not only account for the improved graft patency but may also help to account for the relative absence of atherosclerotic progression in the vascular bed distal to the arterial grafts. ${ }^{18}$ These very properties may be particularly pertinent to the patient with diabetes, enhancing the ability of CABG to address not only the functional obstructions but the underlying pathophysiology. With the rising tide of diabetic vasculopathy, it will become increasingly important to consider both clinical utility and underlying physiology in navigating the uncertain path to optimal patient care.

\section{References}

1. Boyle JP, Thompson TJ, Gregg EW, Barker LE, Williamson DF. Projection of the year 2050 burden of diabetes in the US adult population: dynamic modeling of incidence, mortality, and prediabetes prevalence. Popul Health Metr. 2010; $8: 29$.

2. Goraya TY, Leibson CL, Palumbo PJ, Weston SA, Killian JM, Pfeifer EA, et al. Coronary atherosclerosis in diabetes mellitus: a population-based autopsy study. J Am Coll Cardiol. 2002;40:946-53.

3. Farkouh ME, Domanski M, Sleeper LA, Siami FS, Dangas G, Mack M, et al; FREEDOM Trial Investigators. Strategies for multivessel revascularization in patients with diabetes. $N$ Engl J Med. 2012;367:2375-84.
4. Verma S, Farkouh ME, Yanagawa B, Fitchett DH, Ahsan MR, Ruel M, et al. Comparison of coronary artery bypass surgery and percutaneous coronary intervention in patients with diabetes: a meta-analysis of randomised controlled trials. Lancet Diabetes Endocrinol. 2013;1:317-28.

5. Al Ali J, Franck C, Filion KB, Eisenberg MJ. Coronary artery bypass graft surgery versus percutaneous coronary intervention with first-generation drugeluting stents: a meta-analysis of randomized controlled trials. JACC Cardiovasc Interv. 2014;7:497-506.

6. DeLuca G, Schaffer A, Verdoia M, Suryapranata H. Meta-analysis of 14 trials comparing bypass grafting vs drug-eluting stents in diabetic patients with multivessel coronary artery disease. Nutr Metab Cardiovasc Dis. 2014;24:344-54.

7. Lim JY, Deo SV, Kim WS, Altarabsheh SE, Erwin PJ, Park SJ. Drug-eluting stents versus coronary artery bypass grafting in diabetic patients with multivessel disease: a meta-analysis. Heart Lung Circ. 2014;23:717-25.

8. Ariyaratne TV, Ademi Z, Yap CH, Billah B, Rosenfeldt F, Yan BP, et al. Prolonged effectiveness of coronary artery bypass surgery versus drug-eluting stents in diabetics with multivessel disease: an updated systematic review and metaanalysis. Int J Cardiol. 2014;176:346-53.

9. Wu YC, Su TW, Zhang JF, Shen WF, Ning G, Kong Y. Coronary artery bypass grafting versus drug-eluting stents in patients with severe coronary artery disease and diabetes mellitus: a systematic review and meta-analysis. J Diabetes. 2015;7: 192-201.

10. Bangalore S, Toklu B, Feit F. Outcomes with coronary artery bypass graft surgery versus percutaneous coronary intervention for patients with diabetes mellitus: can newer generation drug-eluting stents bridge the gap? Circ Cardiovasc Interv. 2014; 7:518-25.

11. Nauffal V, Schwann TA, Yammine MB, El-Hage-Sleiman AK, El Zein MH, Kabour A, et al. Impact of prior intracoronary stenting on late outcomes of coronary artery bypass surgery in diabetics with triple-vessel disease. $J$ Thorac Cardiovasc Surg. 2015;149:1302-9.

12. Deb S, Singh SK, Moussa F, Tsubota H, Une D, Kiss A, et al. Radial Artery Patency Study Investigators. The long-term impact of diabetes on graft patency after coronary artery bypass grafting surgery: a substudy of the multicenter Radial Artery Patency Study. J Thorac Cardiovasc Surg. 2014;148:1246-53; discussion 1253.

13. Puskas JD, Sadiq A, Vassiliades TA, Kilgo PD, Lattouf OM. Bilateral internal thoracic artery grafting is associated with significantly improved long-term survival, even among diabetic patients. Ann Thorac Surg. 2012;94:710-5; discussion 715-6.

14. Dorman MJ, Kurlansky PA, Traad EA, Galbut DL, Zucker M, Ebra G. Bilateral internal mammary artery grafting enhances survival in diabetic patients: a 30year follow-up of propensity score-matched cohorts. Circulation. 2012;126: 2935-42.

15. Nishioka H, Kitamura S, Kameda Y, Taniguchi S, Kawata T, Mizuguchi K. Difference in acetylcholine-induced nitric oxide release of arterial and venous grafts in patients after coronary bypass operations. J Thorac Cardiovasc Surg. 1998; 116:454-9.

16. Amoroso G, Tio RA, Mariani MA, Van Boven AJ, Jessurun GA, Monnink SH, et al. Functional integrity and aging of the left internal thoracic artery after coronary artery bypass surgery. J Thorac Cardiovasc Surg. 2000;120:313-8.

17. Tarr FI, Sasvári M, Tarr M, Rácz R. Evidence of nitric oxide produced by the internal mammary artery graft in venous drainage of the recipient coronary artery. Ann Thorac Surg. 2005;80:1728-31.

18. Dimitrova KR, Hoffman DM, Geller CM, Dincheva G, Ko W, Tranbaugh RF Arterial grafts protect the native coronary vessels from atherosclerotic disease progression. Ann Thorac Surg. 2012;94:475-81. 